\title{
MAKING FORMWORK CONSTRUCTION LEAN
}

\author{
Chien-Ho $\mathrm{KO}^{\mathrm{a}}$, Jiun-De KUO ${ }^{\mathrm{b}}$ \\ ${ }^{a}$ Department of Civil Engineering, National Pingtung University of Science and Technology, \\ 1, Shuefu Road, Neipu, Pingtung 91201, Taiwan \\ ${ }^{b}$ Information Center of Construction Industry, Taiwan Construction Research Institute, Taiwan
}

Received 02 Aug 2012; accepted 19 Nov 2012

\begin{abstract}
Formwork material and payroll are among the greatest costs in building reinforced concrete structures. Therefore, formwork engineering is a key factor affecting project success. Traditional formwork construction entails non-value-adding activities resulting in waste. The objective of this study is to adapt lean manufacturing techniques to formwork engineering in a bid to reduce waste, specifically by developing a lean formwork construction model. In the model, andon is used to establish an on-site quality control culture, allowing form workers to obtain assistance immediately whenever a problem occurs. In addition, formwork operations are pulled through the kanban system to reduce mould inventory and achieve continuous construction flow. A case study is used to validate the applicability of the proposed model. Results show that the proposed model can effectively reduce waste in the formwork construction flow and increase the value of operations, thus providing a new approach to improving formwork engineering.
\end{abstract}

Keywords: formwork, lean manufacturing, kanban, andon.

\section{Introduction}

Formwork payroll and material costs account for approximately $15 \%$ of the construction cost and $1 / 3$ of the structure costs for reinforced concrete construction (Peng 1991, 1992). Therefore, formwork engineering directly affects the success of a project (Jones 2003; Umit Dikmen, Sonmez 2011). The formwork construction flows entail wasteful non-value-adding operations and motions (Ko et al. 2011). According to Peng (1998), workers assembling and machining formworks spend $13.5 \%$ of their total time "walking and searching for moulds" and 22.1\% on "searching for required materials from disordered moulds." Moreover, when transporting moulds, workers spend $30.6 \%$ of their time "waiting to move moulds." Progress downtime or expedition is poorly arranged in the formwork schedule (Abdelhamid et al. 2009), and current practices make it difficult to maintaining a stable formwork flow.

Formwork operations depend heavily on teamwork, but the inclusion of ageing workers in work teams may negatively impact productivity. This is a structural problem that directly impacts project delivery, quality, and costs (Sutherland 2005; Chang 2007). To address these issues, scholars have suggested the use of substituting conventional wooden moulds with alternative materials, such as paper, fabric, fibre, Fibre-Reinforced Plastic (FRP), metal, compounds, and composites (Arslan et al. 2005;
Yip, Poon 2008; Veenendaal et at. 2011; Spottiswoode et al. 2012; Kim et al. 2008; Sheikh et al. 2007).

In addition, McCraven (2002), Matcham (2004) and Kim et al. (2011) have suggested that formwork engineering can be thoroughly improved by improving construction methods. However, replacing the traditional formwork may raise several problems. In Taiwan, precast fabrication lost its initial popularity because of problems such as water leakage and changes in living habits (Zhuo, Yaung 2004). Peng (1998) further indicated that the cost, quality, and safety of the formwork is affected by the absence of an on-site engineer, use of the mal-striping method, improper use of crane towers, poor material management, and inappropriate labour management systems. Therefore, improvements to formwork engineering should focus on managerial changes. However, to date, only a few attempts have been made to improve the formwork work flow.

Lean manufacturing is an enterprise management philosophy focused on improving flows which has gained popularity in recent years. An adaptation called Lean Construction was first introduced in the construction industry in the 1990s (Koskela 1992). Various studies have demonstrated that lean construction is a viable alternative management philosophy for helping the construction industry breath through the traditional trade off of costs and time (Ballard 2000; Ko, Chen 2012; Ko 2011, 2010; Best, de Valence 2000). For example, Lajevardi et al.

Corresponding author: Chien-Ho Ko

E-mail:fpecount@yahoo.com.tw 
(2011) analysed concreting tasks using lean concepts to identify activities that contribute to time wastage. Eriksson (2010) investigated how various aspects of lean thinking can be implemented in construction projects and how they affect the performance of supply chain actors. Construction safety can also be enhanced if lean ideas are properly applied (Nahmens, Ikuma 2009; Sacks et al. 2009). Nevertheless, few studies have focused on applying lean principles in formwork engineering. Ko et al. (2011) applied lean manufacturing practices to eliminate waste in formwork engineering through implementing the $4 \mathrm{Ps}$ and 14 principles of the Toyota way to improve formwork practices. However, their proposed methods were limited by a restrictive pool of potential solutions without thoroughly considering root problems found in formwork construction processes, and thus largely ignored issues related to formwork quality and inventory.

This research applies lean manufacturing practices to eliminate waste in formwork engineering by considering construction flow, formwork quality, and form inventory. The paper first reviews important background information before explaining production waste, kanban, and andon. Formwork construction practice is then discussed, followed by the development of a lean formwork construction process. Finally, a case study is presented to validate the applicability of the proposed method. Conclusions and direction for future research are presented at the end.

\section{Background information}

\subsection{Production waste}

Toyota has popularized a production system designed to eliminate waste. Designed primarily by former Toyota executive Taiichi Ohno, the system is characterized by low costs, small batch sizes, and diverse production. Ohno defined waste as any activity which fails to comply with the standard efficiency of the production system and does not create value in either the production line or product development flow. Ohno specified seven valueless activities, described as follows (Ohno 1988):

1. Overproduction:

Overproduction is when production volume exceeds customer demand, leading to excessive inventory and its knock-on effects of excessive storage space requirements, increased production costs, unnecessary work, accelerated machinery depreciation, and increased security costs for securing the inventory. Overproduction often creates a vicious circle leading to more waste, and is identified by Ohno as the worst type of waste.

2. Transport:

Transport waste is the unnecessary movement of products from one location to another or unnecessary movements of raw materials, parts, or finished goods. Transport has many causes, such as poor site layout, improper transport routes, and poor coordination. These problems reduce production capacity and increase production costs.
3. Waiting:

This refers to downtime while workers are prevented from beginning the next step in the process by a lack of tools, parts, or equipment. Downtime caused by the failure of management to make timely decisions can also be regarded as waste.

4. Inventory:

This type of waste refers to unprocessed raw materials, work in progress, or goods which cannot be completed. This can result excess purchasing of raw materials or manufacturing of larger than necessary batches, which leads to longer lead times, and obsolete or unneeded products. Excess inventory leads to the stagnation of raw materials in storage and added costs for handling and storage (Ko 2013).

5. Defects:

Defective products refer to those which have been poorly made and require modification. Defective products take extra time to filter out and, rather than creating value for the enterprise, require additional costs to fix or rework.

6. Motion:

This kind of waste refers to an action which creates no value, such as searching for, fetching, or placing tools. Motion waste is inevitable without appropriate planning for production resources such as production equipment and raw materials.

7. Over-processing:

Over-processing occurs when more work is done than is required by the customer. An example would be using tools which are more precise, complex, or expensive than required, especially when an appropriate yet lower-grade alternative is available.

The Toyota Production System (TPS) is frequently contrasted with mass production in place in western countries. Over the past few decades, industries and firms around the world have endeavoured to emulate this world-class enterprise management system (Liker 2003; Liker, Meier 2006).

\subsection{Kanban and andon}

In Japanese, kanban refers to a signboard, billboard, or bulletin board (Liker 2003). As applied to manufacturing, it refers to a scheduling system that helps determine what to produce, when to produce it, and how much to produce. The concept was first developed in Toyota's stamping production line ( $\mathrm{Li}$, Yang 2009a). In the production line, production signals are triggered the level of material consumption. The most direct manifestation of kanban is decreased inventory. TPS features three types of kanban (Li, Yang 2009b):

1. Production kanban:

This is a tool used between the finished goods storage yard and production line to trigger production in the production system.

2. Material withdrawal kanban:

When workers retrieve required parts from storage, this is used to record the various item numbers and quantities. 
3. Display kanbans:

This static board is installed at the production site, and can be divided into two types: one is used for displaying general information while the other is mainly used for displaying managerial data.

Andon is a manufacturing term referring to a system to notify management, maintenance, and other workers of a quality or process problem. The concept originated from the development of an automatic loom invented by Sakichi Toyoda. The loom was designed to stop whenever a break in the thread was detected and to light an alarm lamp, thus alerting a technician to come and fix the problem. Today, the concept plays a key role in Toyota's manufacturing quality control. Production equipment is equipped with error sensors which will automatically stop the production line when an error is detected. Production lines are also equipped with andon cords which stop the production line when pulled, and production line workers are authorized to pull these cords in the event of a problem. Nowadays this alarm system represents the signal needing assistance (Liker 2003).

\section{Status quo of formwork engineering}

\subsection{Operational process}

As seen in Figure 1, the formwork operational process includes planning and designing, shop drawing preparation, material preparation, mould machining, setting out, formwork assembly, inspection, monitoring, post-pouring concrete touch-up, stripping, and formwork re-support (Shen 1996). The general contractor designs the formwork system, which the subcontractor follows in preparing the shop drawings and materials prior to collecting the required moulds and hardware fittings. If inventory levels are insufficient, the subcontractor re-orders the required materials from suppliers. Mould positions are set out

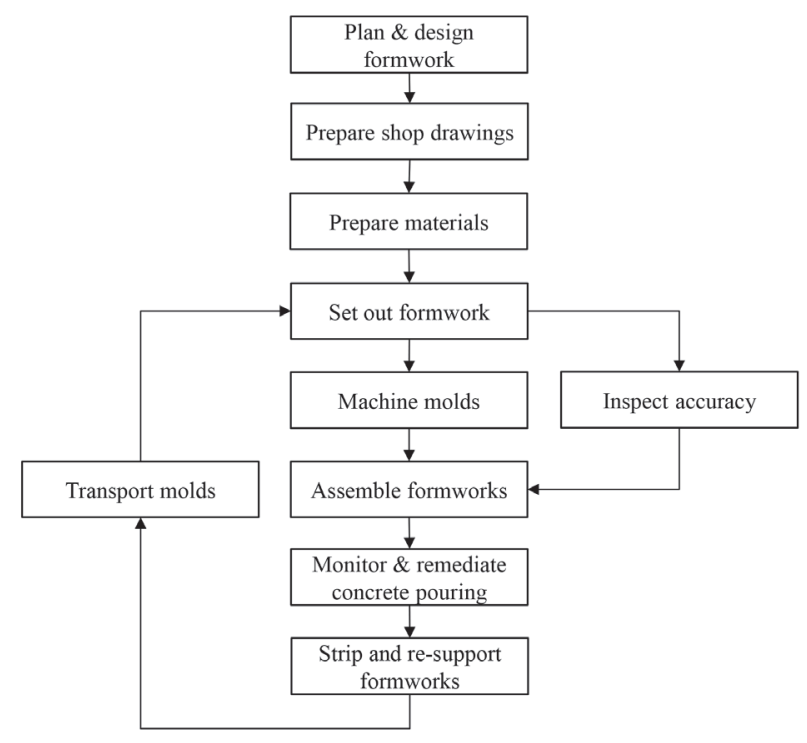

Fig. 1. Formwork operational flow prior to assembly. The formwork subcontractor then verifies the correctness of the setting results prior to moulds machining and assembly. Certain formwork assembly tasks (e.g. piping, rebar, and wiring) are often outsourced to third parties. During concrete pouring, the formwork subcontractor posts a formwork engineer on site to ensure formwork safety and to handle emergencies. Moulds are stripped according to building codes. The stripped moulds are then reused in the next formwork phase, or are shipped to the next project or storage.

To identify waste in the formwork construction flow this research analyses three steps: assembly formwork, machining, and transporting moulds. Data for the analysis are retrieved from Peng (1998), who notes that activities related to assembling and machining formwork can be divided into nine motions: measure, walk, search, pull, cut, pass, wait, nail, and mend, while transporting moulds consists of move and wait. Table 1 summarizes the motions used in formwork operations. While assembling and machining formworks, workers spend $13.5 \%, 22.1 \%$, and $7.9 \%$ of their time walking, searching and waiting, respectively. These activities add no value and are thus regarded as waste caused by inappropriate construction site layout and material storage. As a result, workers spend a considerable amount of their time searching for moulds, hardware fittings, and mould supporters. When transporting moulds, workers spend $47.1 \%$ of handling time waiting, mainly due to again to inefficient site layout, poor moulds placement, and poor labour organization, which idles form workers while other workers are handling the moulds.

To improve efficiency, form workers should create a culture which attaches importance to quality control. If problems are found, formwork progress should be terminated until the problems have been solved. During pouring concrete, defective formworks could collapse, requiring additional costs and manpower to repair the damage. Ultimately, the quality of formwork depends on the skill of the form workers for the following reasons:

1. Formworks are assembled by workers, and thus the quality of the finished formworks varies with the skill with which it is assembled.

2. Mould sizes are standardized, with workers machining moulds into the required sizes on site. The accuracy with which they perform this task affects formwork quality.

3. Form workers clean and repair the moulds, and the diligence with which they perform these tasks directly affects mould availability and reusability.

4. The correctness of worker operations affects formwork system stability.

Defective formwork systems may result in collapse or structure deformation. As shown in Figure 2, poor quality control is the main cause of formwork failure, which results in waste through the production of defective products. Failure of workers to fix problems immediately upon discovery may lead to formwork collapse or structural deformation when the concrete is poured, 
Table 1. Formwork operation analysis

\begin{tabular}{l|l|l|r}
\hline Operation & \multicolumn{1}{|c|}{ Motion } & \multicolumn{1}{c|}{ Description } & Time, $\%$ \\
\hline \multirow{5}{*}{ Assemble \& machine formworks } & Measure & Measure the size of the required formwork & 6.8 \\
\cline { 2 - 4 } & Walk & Walk to the mold storage area & 13.5 \\
\cline { 2 - 4 } & Search & Search for required materials among molds & 22.1 \\
\cline { 2 - 4 } & Pull & Pull nails out of the molds & 3.8 \\
\cline { 2 - 4 } & Machine & Cut mold materials & 2.3 \\
\cline { 2 - 4 } & Pass & Pass molds to workers & 9 \\
\cline { 2 - 4 } & Wait & Wait while an assistant looks for materials & 7.9 \\
\cline { 2 - 4 } & Nail & Nail molds in position & 31.3 \\
\cline { 2 - 4 } & Mend & Mend gaps between molds & 3.6 \\
\hline & Move & Move the stripped molds to the next area & 52.9 \\
\cline { 2 - 4 } & Wait & Wait for transporting & 47.1 \\
\hline
\end{tabular}

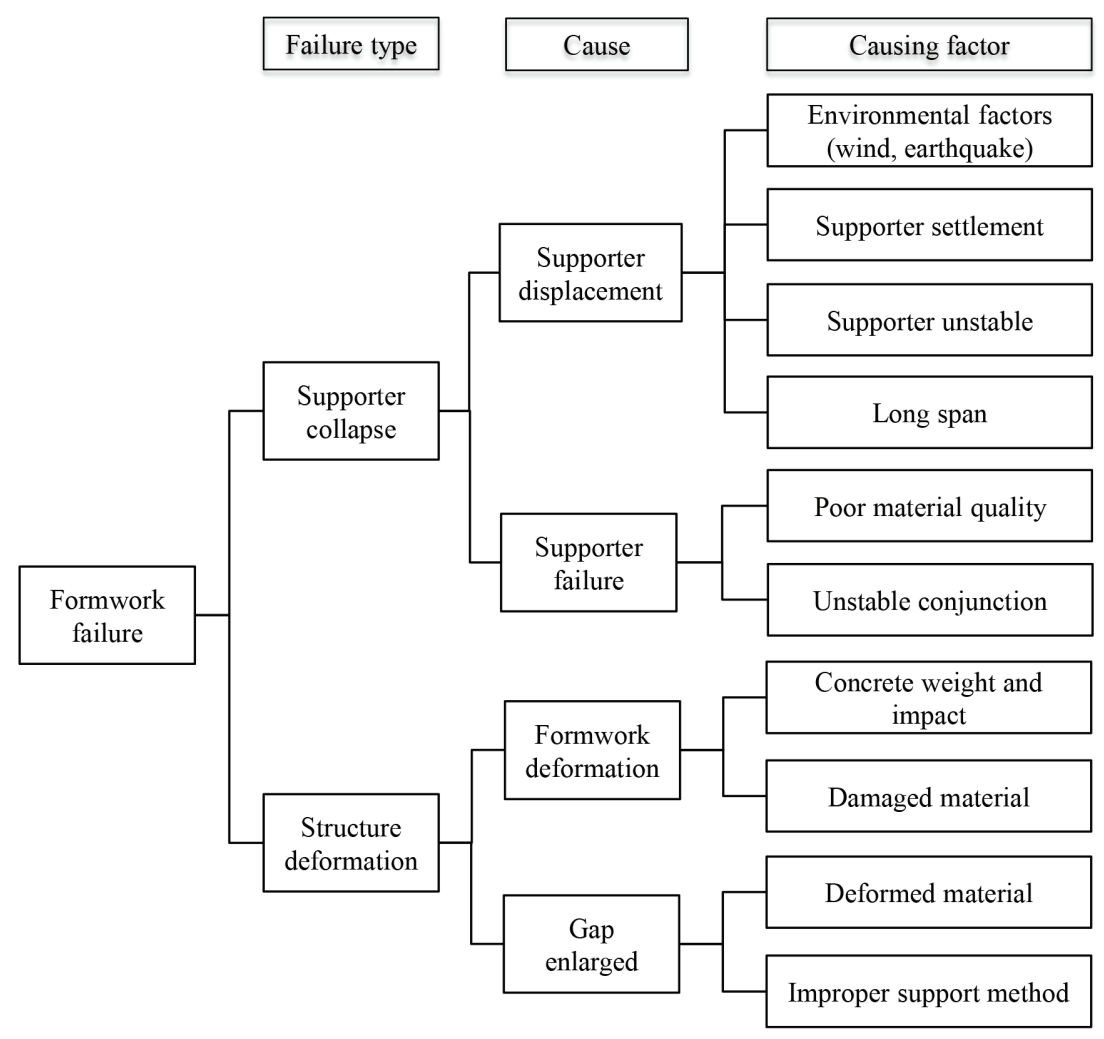

Fig. 2. Causal analysis of formwork failure

thus requiring additional cost, time, and effort to repair the damage, along with the ancillary costs of additional handling procedures required.

\subsection{Value stream}

Formwork construction invests the limited resources to produce tangible products or intangible services with capital value. This study divides the construction flow into material and information flows. In the material flow, the subcontractor first reviews the construction schedule with the formwork foreman and superintendent, ascertains the mould inventory in the storage yard. In the event that inventory is insufficient, orders additional materials. In the information flow, the master schedule is generated by the general contractor. The superintendent and formwork foreman then establish the project schedule and completion time. Based on these documents, the formwork foreman arranges the required manpower. Formwork operations frequently entail waiting wastage, during such activities as retrieving materials from storage, lofting, assembly and machining, mould stripping, mould arranging, and mould transport. Depending on project requirements, the moulds are then transported to another construction site or storage yard. The formwork foreman finally reports project completion to the general contractor. Value stream mapping (VSM) is a popular tool used to identify waste while implementing lean construction (Picchi, Granja 2004; Klotz et al. 2007; Bertelsen, Bonke 2011). Figure 3 presents a 


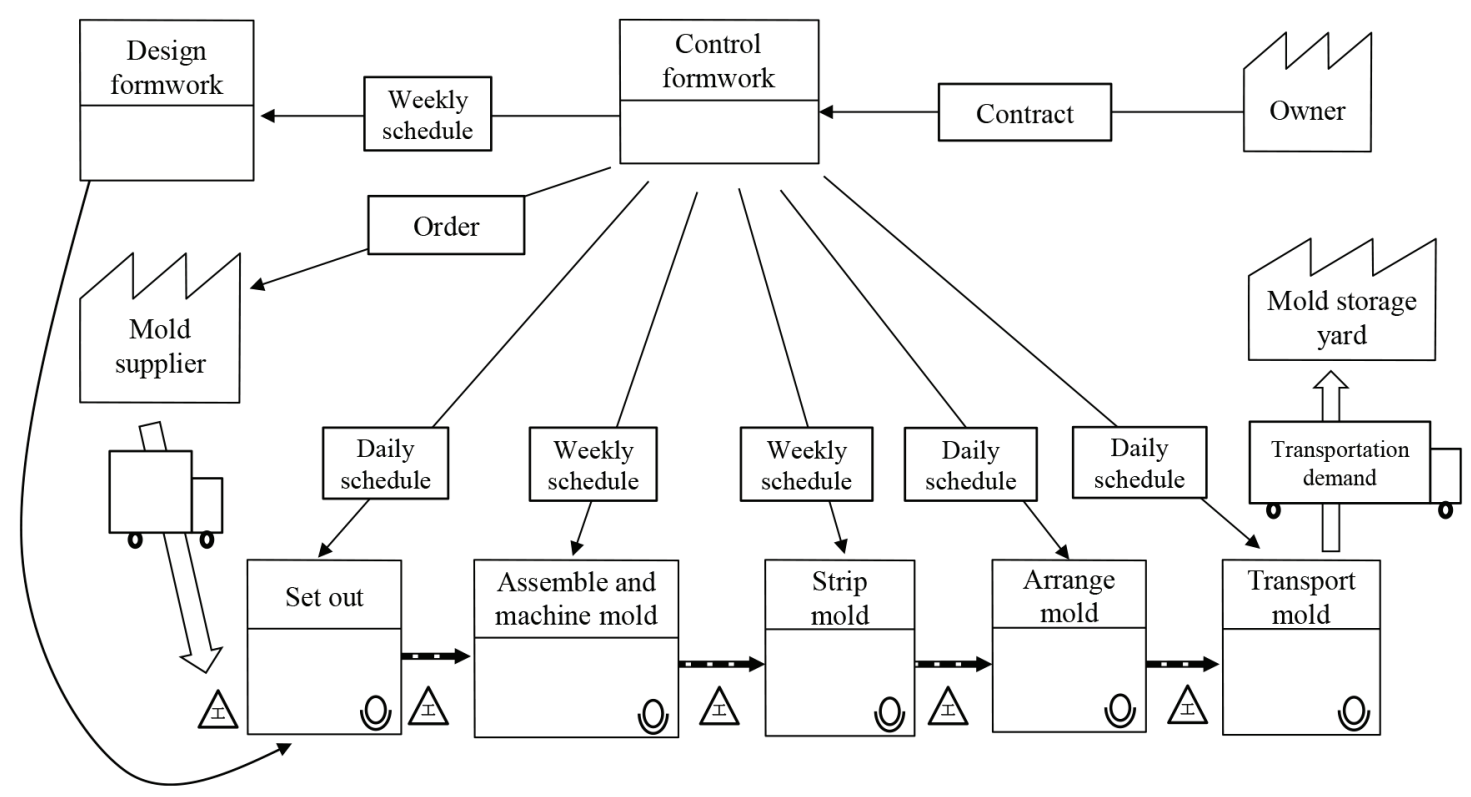

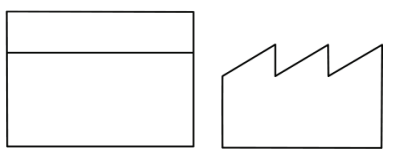

Manufacturing Outside sources process

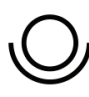

Operator Schedule

Manual
information flow
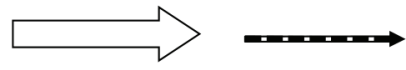

Finished goods to customer

Push arrow
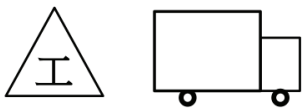

Inventory

Truck shipment

Fig. 3. Value stream map for current formwork construction practices

value stream map to represent this flow, revealing several potential problems in current formwork engineering:

1. Excess inventory is spread among all stations from material delivery to mould transport.

2. The general contractor and other managers may be unaware of onsite problems or product defects.

3. The formwork subcontractor outsources work to third parties (e.g. scaffolding, rebar, electromechanical equipment, and concrete work). Waste may occur while one subcontractor waits for another to complete a particular task.

4. As far as formwork engineering is concerned, the skill and experience of crew members should be considered in addition to the foreman's leadership and capability. Inexperienced workers could produce substandard or defective formwork which requires repair, thus increasing project duration and cost.

\section{Lean formwork construction model}

\subsection{Model architecture}

The general contractor produces the design which governs the construction of the formwork system. Current practice rarely emphasizes the quality of formwork construction or provides a means to improve quality, resulting in inconsistent quality, which could lead to structural deformation or collapse. Furthermore, the arbitrary stockpiling of moulds in the storage yard increases the time required for searching and handling (Peng 1998). To remedy these problems, this study uses the andon and kanban system to establish a lean formwork construction model. Andon is mainly used for establishing a culture of quality control, while the kanban system is used to minimize inventory. Figure 4 shows the framework of the lean formwork construction model.

The Toyota production system attaches considerable importance to the establishment of a quality control culture. When a problem occurs, the production process is immediately stopped until the problem is solved (Liker, Meier 2006). In the lean formwork construction model, andon culture helps form workers stop working and seek help when problems occur. Establishing this culture requires convincing form workers that support is available and that no one will be penalized when problems occur, thus encouraging the development of a cooperative

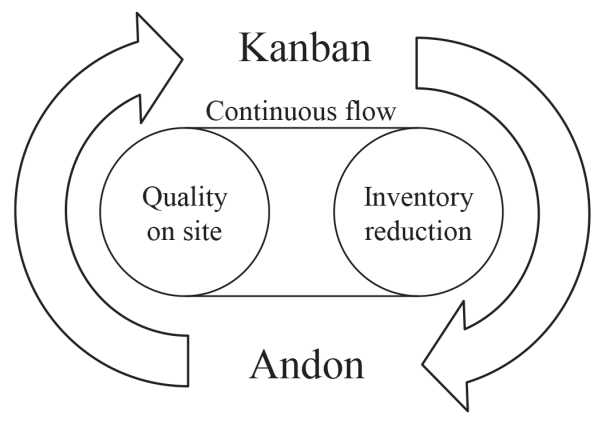

Fig. 4. Framework of lean formwork construction model 
attitude towards performance improvement. Andon culture helps to develop a quality management system that focuses on quality from the outset. Such a culture can also help project stakeholders (e.g. the general contractor, formwork subcontractor, third parties, etc.) identify and solve problems. However, suspending formwork progress puts considerable pressure on project delivery times and costs, thus the various construction teams must work together to identify problems and solutions to minimize waste associated with the downtime. Suspension of production can also effectively control the spread of problems. In current practices, formwork subcontractors generally attribute mistakes to form workers. By contrast, in the lean formwork construction model, all mistakes are assumed to be the result of improper work systems, flows, and methods. Including form workers in such a culture reduces defensiveness and allows team members to focus on finding effective solutions.

The kanban system is used to change the traditional way of orally transmitting construction orders, thus improving communication with clients and reducing potential material waste in the storage yard. In addition, the kanban system can be used by superintendents, formwork foreman, and workers as a basis for communication and joint problem solving. Combining these two approaches allows for the creation of a continuous formwork construction flow to better control the formwork progress.

\subsection{Andon culture}

In TPS, the andon system equips production lines with warning lamps that lights up when a problem is encountered, thus summoning technical personnel to solve the problem (Liker 2003). Managers, on the other hand, are focused on maintaining an uninterrupted project progress flow. In current formwork engineering practice, defective products are usually simply patched in an attempt to deal with defective formwork in a way that does not stop production. When the stage goal has been achieved, the next stage immediately commences. Thus problems caused by defective work and the root causes of defective products are rarely discussed. Allowing defective products to flow into the next operation stage not only creates waste through the production of defective products, but potentially renders all downstream efforts valueless. Therefore, any defective products should be contained within the current stage by terminating construction progress.

This study develops a formwork for an andon culture based on the particular characteristics of formwork. Not all form workers have the same construction skills. When facing technical problems (e.g. unstable conjunctions, etc.), they can seek assistance from their foreman, thus potentially preventing defects from flowing into the next stage. This study proposes a method for applying andon to formwork engineering as follows.

The formwork foreman leads a crew composed of workgroups made of two to four workers. The more skilled and experienced workers are appointed as group leaders. The group leaders and foreman communicate on the site via walkie-talkies. When a group leader encounters a problem he doesn't know how to resolve, the group stops work and the group leader solicits assistance from the foreman via the wireless device. Once the problem is resolved, the workers resume their work.

The main purpose of this method is to provide workers with immediate assistance when problems occur, thus eliminating waste in two ways:

1. The andon system establishes a culture of on-site quality control to reduce defects resulting from inadequate worker skills.

2. Reducing the incidence of defects also reduces waste from actions associated with repairing those defects, i.e. transporting, assembly, and machining replacement formworks.

\subsection{Kanban system}

Traditional formwork engineering tasks are assigned orally without providing specific production information. Lacking clear or complete information, workers may generate waste through overproduction and unnecessary action. In this study, the kanban system is used for delivering construction orders, thus reducing waste, reducing inventories of incomplete and finished formworks, and allowing accurate monitoring of mould inventory and production lead time. In this study, four kanbans are used. The construction kanban is used for delivering the construction orders; the material withdrawal kanban is used for retrieving parts; the mould storage yard display kanban is used to display storage yard information; and the signal kanban is used for alternating subcontractor activities. The function of each kanban is further below:

1. Construction kanban

This kanban is mainly used by the formwork foreman to deliver clear construction orders to the group leader before construction. Each kanban specifies half-day jobs, indicating the relevant time, quantity, construction items, construction location, and mould storage yard location. The entire formwork construction process can be pulled through the kanban, with an example shown in Figure 5.

\section{Material withdrawal kanban}

This kanban is mainly used by workers removing materials from the storage yard to the construction location. The foreman prepares the kanban for the group leader when the construction kanban is delivered. The material withdrawal kanban specifies the quantities and locations of moulds, hardware fittings, and supporters. When implementing formwork construction, the group leader gives this kanban to the form workers to retrieve the needed material, thus reducing time previously spent on searching for moulds.

\section{Storage yard display kanban}

As shown in Figure 6, this kanban is mainly used for displaying the information related to the working area, moulds, hardware fittings, supporter locations, and reorder point. The formwork subcontractor sets this kanban in an easily-accessible location in the working area to 


\begin{tabular}{|l|l|l|}
\hline \multicolumn{2}{|c|}{ Formwork construction kanban } \\
\hline Construction time & MM DD YY & \multirow{2}{*}{ Photos: (completion } \\
Construction location & & \\
\hline Construction quantity & & \\
\hline Previous construction activity & & \\
\hline Next construction activity & & \multirow{2}{*}{ Tel: } \\
\cline { 1 - 2 } Storage yard location & & \\
\hline Number of workers & & \\
\hline Remarks & & \\
\hline
\end{tabular}

Fig. 5. Formwork construction Kanban

\begin{tabular}{|l|l|l|l|}
\hline \multicolumn{3}{|c|}{ Formwork storage yard display kanban } \\
\hline Material name & \multicolumn{2}{|l|}{} \\
\hline Number of reuse & \multicolumn{2}{|l|}{} \\
\hline Material & & Responsible person & \\
specifications & & & \\
\hline Inventory & & Telephone & \\
\hline Remarks & (reorder point) & & \\
\hline
\end{tabular}

Fig. 6. Formwork storage yard display Kanban

help the crew members understand the layout of the storage yard. This kanban is used to reduce the time spent looking for materials and, through the reorder point information, remind the foreman to order additional formwork materials as needed.

\section{Signal kanban}

In this study, the signal kanban is mainly to alert workers to changes in construction activity. In formwork operations, assembling and machining formworks is a continuous operation. However, mould removal is restricted by building codes, which can disrupt the assembly and machining process. In this study, the signal kanban is used to unify the formwork construction flow.

\subsection{Site layout planning}

If moulds are scattered arbitrarily around the construction site, workers need to spend considerably more time searching for the required moulds (Peng 1998). Figure 7 shows a scene from an actual formwork site. To mitigate this problem, planning principles are proposed to eliminate non-value-adding activities including waiting, walking and searching.

Figure 8 illustrates the principles for site layout planning. Materials of different sizes are placed in dif- ferent areas to reduce the time required for searching for and returning moulds. The mould machining area should be as close as possible to the staging area (e.g. in the middle of the construction area) reduce walking time. The discarded mould area can be set in a corner to avoid hindering material storage and onsite traffic. The workers' rest area and meeting area can be planned according to actual project requirements. Material partition principles are explained as follows:

- Material storage area (A1-A5):

Needed materials including moulds, wooden supports, and hardware fittings are placed in different areas, thus reducing wasted motion such as walking and searching in the assembly and machining of formworks. These materials are then returned to their designated storage areas, thus reducing waiting time.

Formwork materials can be organized in different areas according to their functions: complete moulds (A1), support and hardware fitting (A2), class 1 moulds (A3), class 2 moulds (A4), and discarded moulds (A5)

- Material machining area (B):

Prior to assembly, moulds are cut into appropriate sizes according to the shop drawing in the formwork machin- 


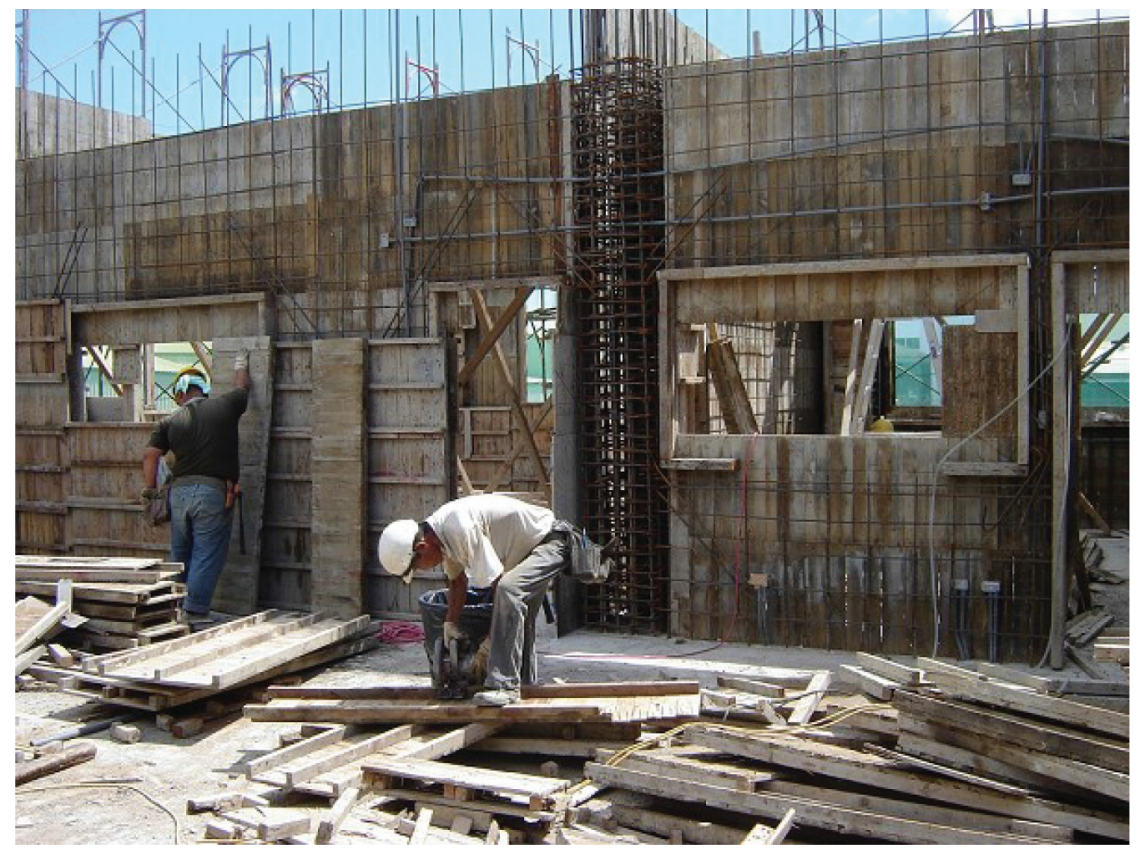

Fig. 7. Formwork construction site showing inefficient mould storage

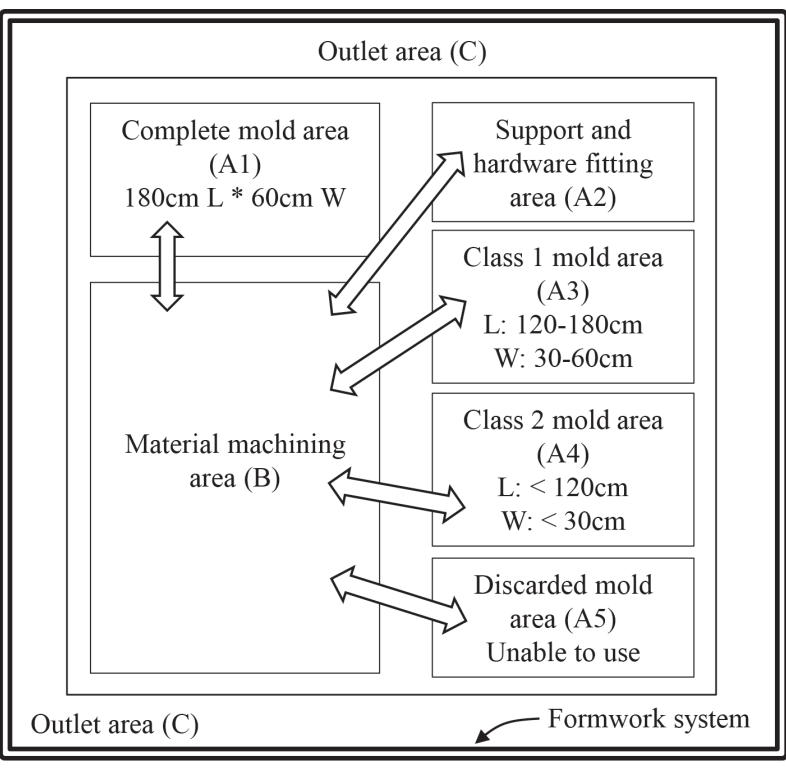

Fig. 8. Formwork construction site layout

ing area (B), located in the most easily accessible area to reduce wasted motion (e.g. walking).

- Outlet area (C):

To expedite material movements, the outlet areas are located in the outer part of the formwork construction area known as the material outlet area (C). Form workers can retrieve materials directly from the storage yards, thus reducing time otherwise spent waiting, walking, and searching.

\subsection{Future formwork construction process}

Figure 9 shows the value stream mapping of the proposed lean formwork construction model. The formwork subcontractor levels the assembly and machining formwork workload (heijunka) according to the general contractor's master construction and weekly schedules. Regarding the material flow, the formwork subcontractor confers with the superintendent about the master schedule. The subcontractor then inventories the required moulds, support, and fittings. The needed formwork materials are also sent to the project storage yard. Regarding the information flow, the general contractor arranges a schedule for the formwork engineering. The formwork schedule is then jointly organized by the superintendent and formwork foreman. Finally, the foreman follows the formwork schedules in distributing labour resources.

Upon the completion of preparation work, formwork assembly and machining triggers setting out activity on site. Based on assembly and machining requirements, formwork material is retrieved using supermarket driven using the withdrawal kanban. During the mould machining process, any doubts about the required mould sizes should prompt workers to stop operations and request assistance from the on-site engineer or formwork foreman. Meanwhile, the formwork foreman examines inventory levels according to the storage yard display kanban. When inventory levels drop below the pre-determined reorder point, the subcontractor reorders materials.

This method can significantly reduce mould inventory on site. Local regulations determine how long moulds have to stay in place prior to stripping, and the signal for mould stripping is initiated using the formwork removal kanban. For instance, side moulds for pillars, beams, and walls must stay in place 12 hours. Following stripping, a determination is made if the stripped moulds need to be used immediately elsewhere on the job site, or if they should be sorted and transported to the storage yard on a first-in-first-out basis. 


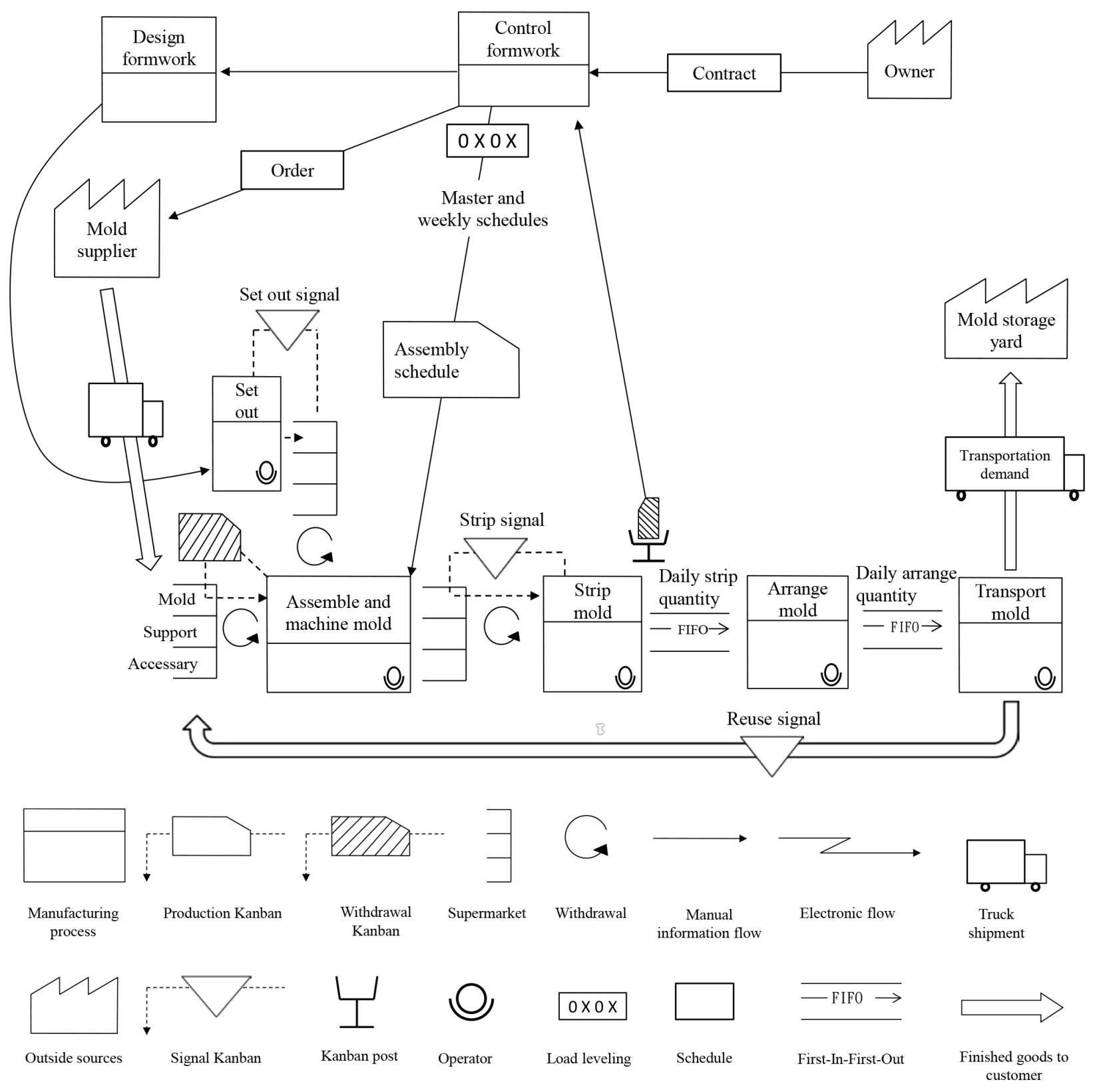

Fig. 9. Future formwork value stream mapping

\section{Case study}

\subsection{Background}

This paper presents an actual construction case from Taiwan to illustrate the feasibility of the proposed lean formwork construction model. The main structure has four stories and one basement level, with a total floor of 2185.3 square meters. This study focuses on the formwork construction in the second floor. The formwork area in the second floor totals 1646 square meters, and is accomplished using wooden moulds, wooden supports, steel tube supports, and shaped steel. Aside from formwork subcontractors, the project involves scaffolding, rebar, electromechanical, and concrete engineering work. Table 2 summarizes the worker-hours deployed to complete this floor. Data were collected on site, with

worker-hours averaged over a one month period of observation.

\subsection{Current-state value stream mapping}

To understand the site's formwork operational flow, Figure 10 presents the current-state value stream map. In between setting out the formworks and storage yard preparation, the formwork subcontractor had to wait for the rebar construction team, wasting 20 hours. Another 32 hours of waiting occurred between storage yard preparation and the formwork assembly and machining stage while the formwork subcontractor waited for the scaffolding crew. A total of 1124 worker-hours were spent on the assembly and machining of 1646 square meters of formwork. Formwork productivity can be calculated by dividing formwork quantity by the number of workers (Chang 2007). In this 
Table 2. Formwork construction worker-hours

\begin{tabular}{lc}
\hline Activity & Worker-hours $^{1}$ \\
\hline Set out formworks & 4 \\
\hline Prepare storage yard & 16 \\
\hline Assemble and machine mold & 1124 \\
\hline Strip mold & 212 \\
\hline Arrange mold & 114 \\
\hline Transport mold & 282 \\
\hline${ }^{1}$ worker-hours $=$ Workers $* 8$ hours.
\end{tabular}

case, the average productivity is 11.72 square meters (i.e. $1646 / 140.5)$ per day per worker. A total of 280 workerhours were spent on mould transport for an average of 46.7 square meters per day per worker.

\subsection{Site layout}

An appropriate formwork site layout can reduce wasted action including walking, searching, and waiting. As shown in Figure 11, this study divides the work area into two formwork storage yards. In each storage yard, the estimated required material is positioned according to its place in the production sequence. When assembling and machining formworks, workers can easily retrieve materials from the storage yard, reducing time wasted on unnecessary walking, searching, and waiting. Immediately after stripping, workers sort and replace the materials in the appropriate storage location, thus further reducing unnecessary waiting time. When a certain amount of moulds have been collected they are delivered to the next floor.

\subsection{Kanban system and andon culture}

As shown in Figure 12, display kanbans are positioned in highly visible locations in the storage yard to help workers find and replace formwork materials. From the display kanban, the formwork foreman can ascertain material reuse times, allowing him to visually assess material usage conditions. Overused and damaged materials can be discarded to avoid defects.

Formwork construction is driven by the information contained in the construction instruction, material withdrawal, and signal kanbans. Figure 13 shows an example of a signal kanban used to signal a change in construction activity, e.g. scaffold, rebar, electromechanical, or concrete engineering. The first job in formwork engineering is to set out the formwork positions. The foreman prepares the construction kanban to specify shop drawing, location, quantity, worker, previous construction item and next construction item. The workers then follow this information to implement formwork operations. The instruction kanban improves operational continuity by specifying the previous and next construction items. The next work item (e.g. shipping materials to site) cannot proceed until the previous work item (e.g. concrete pouring) has been confirmed completed. Moreover, when confronted by problems that may affect construction progress (e.g. illegible drawings, undetermined construction locations, or broken equipment) the andon culture encourages workers to stop the process and seek help from their group leader. This involvement in the problem-solving process helps workers develop their own skills, creating a culture of continuous improvement which further enhances formwork quality.

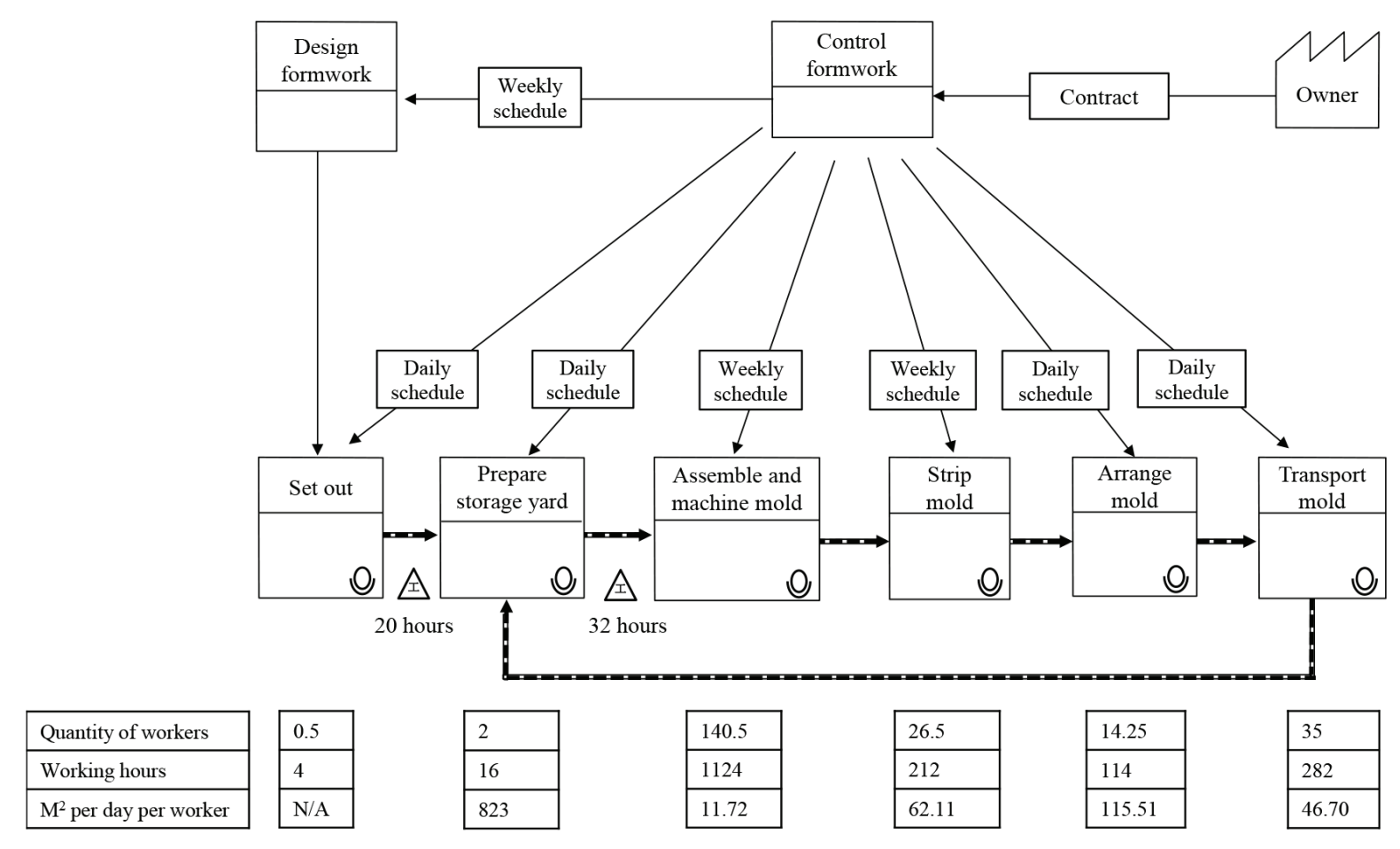

Fig. 10. Current-state value stream mapping of the case study 


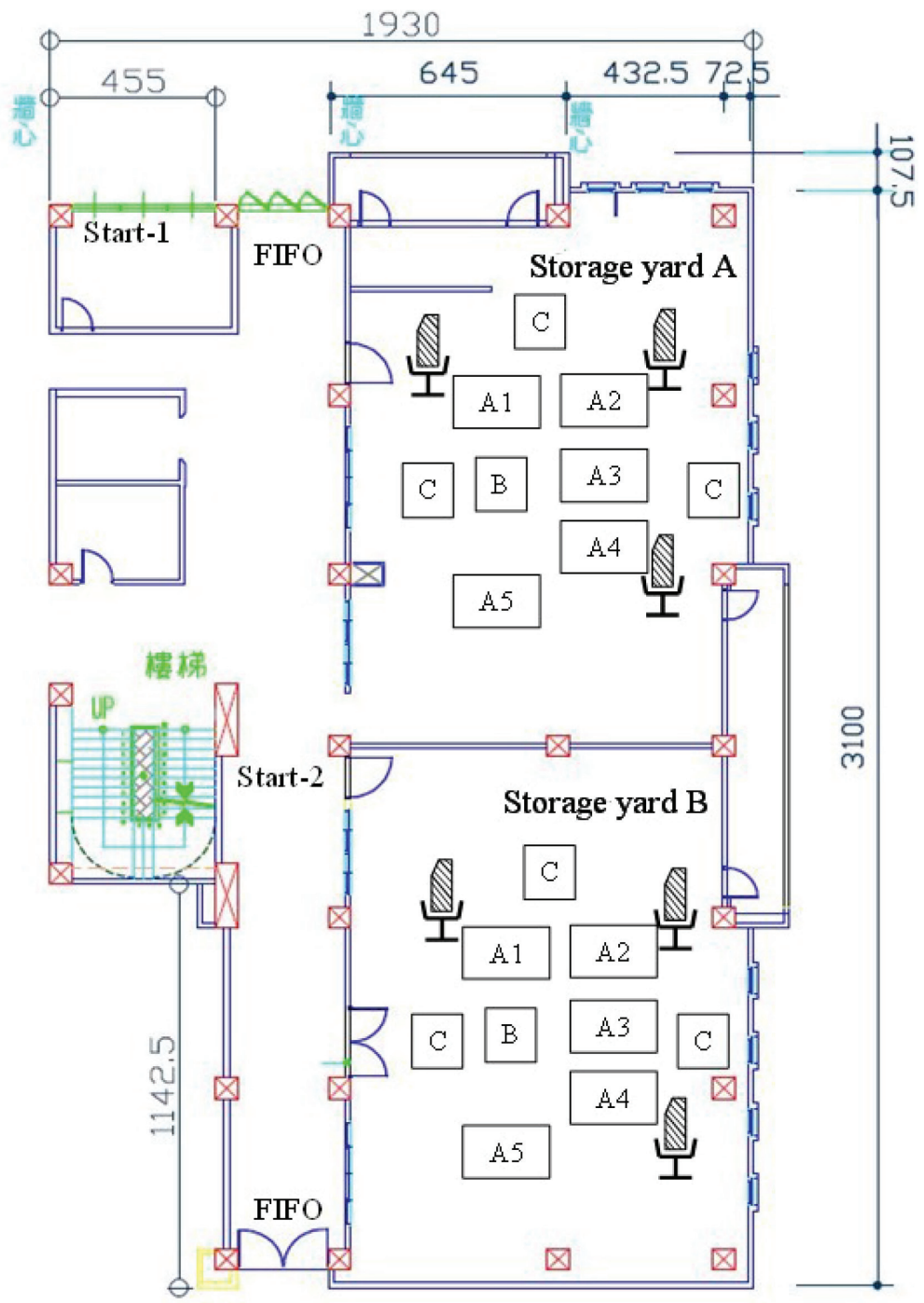

Fig. 11. Site layout

\begin{tabular}{|l|c|l|r|}
\hline Material name & Wooden mold \\
\hline Number of uses & \multicolumn{3}{|c|}{2 (use number is painted on the mold) } \\
\hline Material & $180 * 60$ & Responsible & John Smith \\
specifications, cm & 100 sheets & Telephone & 09123456 \\
\hline Inventory & \multicolumn{3}{|l}{} \\
\hline Remarks & & \\
\hline
\end{tabular}

Fig. 12. Formwork display Kanban

\subsection{Improvement analysis}

Table 3 presents a motion analysis for the case study, based on the worker-hours in Table 2 and the formwork motion analysis in Table 1, which shows the motions involved in two activities analysed in the case study. Those motions (i.e. assembling and machining formworks, and transporting moulds) are identified by Peng (1998) as standard operational motions in formwork en- gineering. By applying motion analysis to current practices, one can derive the motions involved in formwork assembling and machining, and mould transporting at the case study site.

In formwork assembly and machining, actions including measuring, pulling, cutting, passing, nailing, and mending are value-adding activities, whereas walking, searching, and waiting are waste. The movement involved in trans- 
18.97 to 6.46 , and the number of worker-hours from 151.74 to 51.7 . Subtracting non-adding-value motions, worker-hours employed in formwork assembly and machining is reduced from 1124 to 686.72 . When transporting moulds, workers promptly sort and return the stripped moulds to their assigned storage location. Moulds are sent to the next construction location on a first-in-first-out basis, thus gradually reducing waiting time by 132.96 worker-hours.

Eliminating walking, searching, and waiting from formwork assembly and machining, and waiting in mould transport can reduce total worker-hours by 570.24 . The proposed method eliminates 437.28 wasted worker-hours in the formwork assembly and machining process, raising productivity from an initial 11.72 square meters per worker per day to 19.18. Productivity in mould transport increases from an initial 46.7 square meters per worker per day to 88.35 . Figure 14 illustrates improvements at the same location.

\subsection{Future-state value stream mapping}

Traditional formwork management is organized around a completion-oriented culture which disregards the value of construction flow. The formwork foreman rarely seeks group-wide consensus and gives little thought to continuous construction flow. As a result, workers tend to focus on their own tasks in isolation. This study adapts lean manufacturing concepts to improve the current flow.

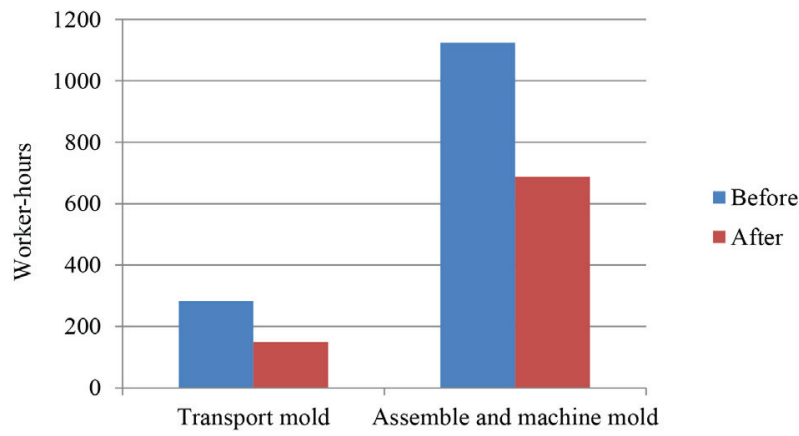

Fig. 14. Worker-hours improvement

Site layout is planned to eliminate wasted actions such as searching and waiting in formwork assembly and machining, and waiting during mould transport. The kanban system is used to establish a continuous construction flow and reduce on-site inventory. Figure 15 illustrates the future-state formwork value stream mapping.

\subsection{Discussion}

In current practice the general contractor, formwork subcontractor, and third parties approach project work individually. This lack of an integral plan results in poor coordination which leads to wasted time as subcontractors wait for one another to complete their tasks. Table 3 shows that the current formwork construction flow contains several types of waste action, which is mainly at-

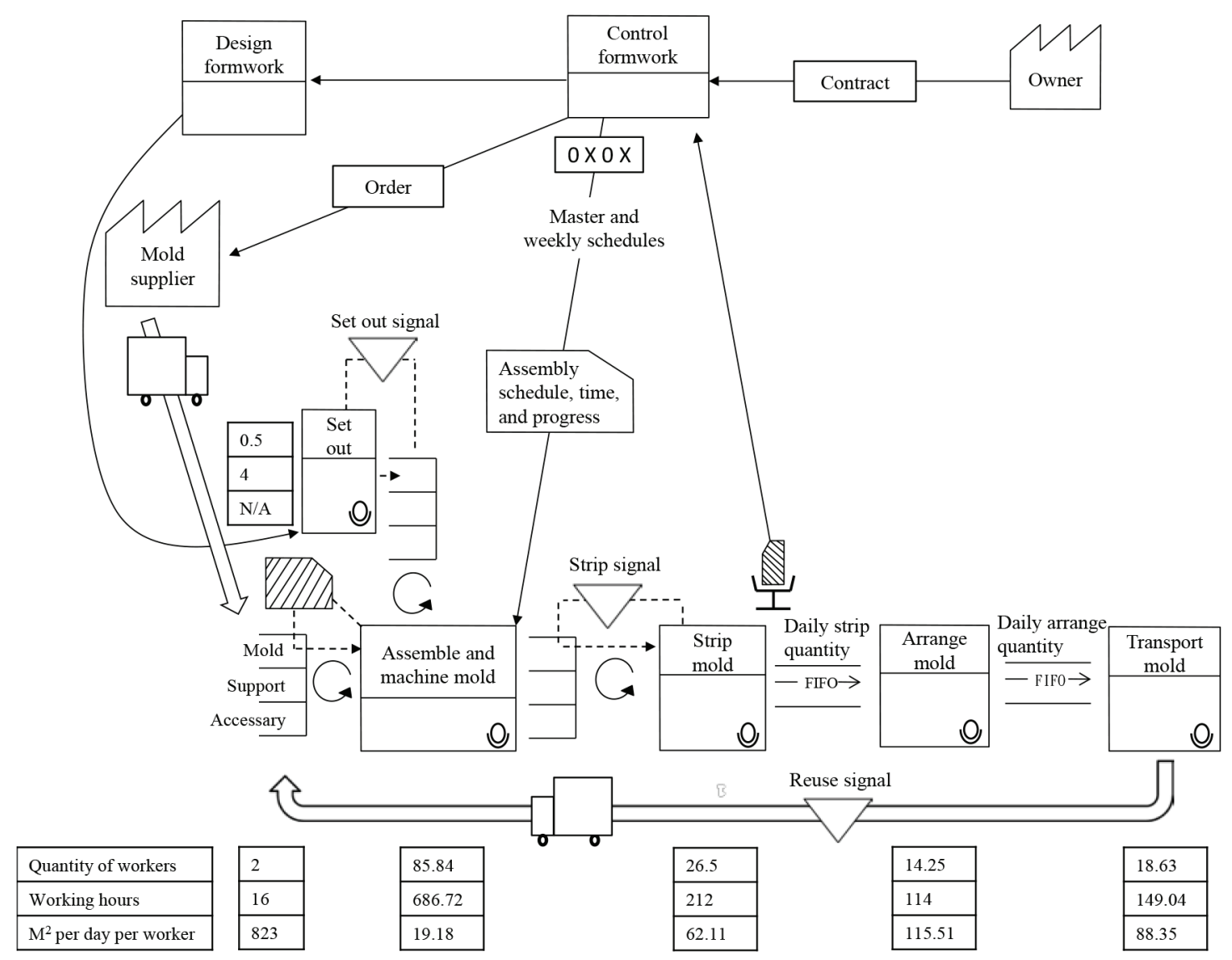

Fig. 15. Future-state formwork value stream mapping 
tributable to the formwork foreman failing to effectively plan the construction site layout. This results in wasted action including walking, searching and waiting during formwork assembly and machining, and during mould transport. Furthermore, formwork tasks are assigned orally by the foreman, potentially resulting in form workers receiving incomplete production information. Moreover, the formwork team generally lacks a strong concept for on-site quality control, and workers have trouble securing assistance in dealing with problems in the construction process. These issues can result in waste through the production of defective products.

This study adopts the andon approach to improving formwork construction. The kanban system is used to improve communication between stakeholders and form an integrated construction team. The site layout is planned according to the material partition principles shown in Figure 11. The configuration of the work area is determined according to material storage locations and constructability. Improved communication and site layout can reduce waste actions including walking, searching, and waiting in the process of assembling, machining, and transporting moulds. Form workers can use trolleys to move moulds from storage to the worksite, thus reducing waste from unnecessary walking. In addition, as shown in Figures 12 and 13, the kanban system can be used to improve communication between workers and the foreman, thus smoothing the transition into the following activity in the formwork construction flow. This study also emphasizes on-site quality control. The proposed approach allows form workers to immediately stop production in the face of problems and request assistance, thus preventing wastage through the production of defective products and avoiding the knock-on effects of those defects being sent into the downstream construction flow.

\section{Conclusions}

Current practices in formwork assembly, machining, and transport entail considerable waste. This research adapts lean manufacturing practices to establish a lean formwork construction model to reduce waste while increasing customer value. The kanban system is used to optimize mould inventory while creating a continuous formwork construction flow, allowing for improved progress control. A case study shows that the proposed lean formwork construction model can reduce waste in the process of assembling, machining, and transporting moulds, thus increasing customer value.

Improving formwork quality depends on adopting a culture of continuous learning and improvement. The andon culture and kanban system can then be used to eliminate waste. However, in implementing such a system, the foreman and superintendent must take into account the potential for resistance to change. Implementing the lean formwork construction model would require extensive education and training. While the current study focuses on the mould assembly, machining, and transport processes, future research can apply the model to improve other formwork operations. In addition, the proposed model has potential for application to enhance other construction activities such as steel erection, rebar installation, and concrete pouring. However, minor revisions will have to be made to account for the unique characteristics of the various activities.

\section{References}

Abdelhamid, T.; El-Gafy, M.; Mitropoulos, P. 2009. Selection of roof casting formwork systems for the bird island project: Case study, Practice Periodical on Structural Design and Construction 14(4): 224-241.

http://dx.doi.org/10.1061/(ASCE)SC.1943-5576.0000002

Arslan, M.; Simsek, O.; Subasi, S. 2005. Effects of formwork surface materials on concrete lateral pressure, Construction and Building Materials 19(4): 319-325. http://dx.doi.org/10.1016/j.conbuildmat.2004.07.007

Ballard, G. 2000. The last planner system of production control: PhD Thesis. The University of Birmingham, UK.

Bertelsen, S.; Bonke, S. 2011. Transformation-flow-value as a strategic tool in project production, Lean Construction Journal IGLC Special Issue: 33-40.

Best, R.; de Valence, G. (Eds.). 2000. Building in value: project delivery. New York: John Wiley \& Sons, 11-25.

Chang, H. C. 2007. Productivity analysis of construction formwork in residential buildings: MS Thesis. Department of Civil Engineering, National Taiwan University, Taiwan (in Chinese).

Eriksson, P. E. 2010. Improving construction supply chain collaboration and performance: a lean construction pilot project, Supply Chain Management: An International Journal 15(5): 394-403.

Kim, G. B.; Pilakoutas, K.; Waldron, P. 2008. Development of thin FRP reinforced GFRC permanent formwork systems, Construction and Building Materials 22(11): 2250-2259. http://dx.doi.org/10.1016/j.conbuildmat.2007.07.029

Kim, J. H.; Beacraft, M. W.; Kwon, S. H.; Shah, S. P. 2011. Simple analytical model for formwork design of selfconsolidating Concrete, ACI Materials Journal 108(1): $38-45$.

Klotz, L.; Horman, M.; Bodenschatz, M. 2007. A lean modeling protocol for evaluating green project delivery, Lean Construction Journal 3(1): 1-18.

Ko, C. H. 2010. An integrated framework for reducing precast fabrication inventory, Journal of Civil Engineering and Management 16(3): 418-427.

http://dx.doi.org/10.3846/jcem.2010.48

Ko, C. H. 2011. Production control in precast fabrication: considering demand variability in production schedules, Canadian Journal of Civil Engineering 38(2): 191-199. http://dx.doi.org/10.1139/L10-123

Ko, C. H. 2013. Material transshipment for precast fabrication, Journal of Civil Engineering and Management 19(3): 335-347.

Ko, C. H.; Chen, Y. C. 2012. Evaluating production time buffer for precast fabrication, Journal of Engineering, Project, and Production Management 2(2): 101-111.

Ko, C. H.; Wang, W. C.; Kuo, J. D. 2011. Improving formwork engineering using the Toyota way, Journal of Engineering, Project, and Production Management 1(1): 13-27.

Koskela, L. 1992. Application of the new production philosophy to construction. Technical Report. Stanford University, USA. $75 \mathrm{p}$.

Jones, Ed. 2003. Estimating costs for wood formwork fabricated onsite, Concrete Construction-World of Concrete 48(4): $54-55$. 
Lajevardi, A.; Endut, I. R.; Paydar, S. 2011. Application of lean model to reduce waste of time in construction. Case study of concreting task in Malaysia, IEEE Colloquium on Humanities Science and Engineering (CHUSER), 5-6 December 2011, Penang, Malaysia, 345-350.

Li, H. S.; Yang, C. C. 2009a. Meticulously discuss Toyota production system, Quality Monthly Journal 45(3): 13-18 (in Chinese).

Li, H. S.; Yang, C. C. 2009b. Kanban in Toyota production system, Quality Monthly Journal 45(4): 42-49 (in Chinese).

Liker, J. K. 2003. The Toyota way: 14 management principles from the world's greatest manufacturer. New York: McGraw Hill. 350 p.

Liker, J. K.; Meier, D. 2006. The Toyota way fieldbook. New York: McGraw Hill. 288 p.

Matcham, H. 2004. Innovative formwork helps Wembley kick off, Concrete 38(2): 34-36.

McCraven, S. C. 2002. Imported formwork innovations, Construction-World of Concrete 47(10): 37-40.

Nahmens, I.; Ikuma, L. H. 2009. An empirical examination of the relationship between lean construction and safety in the industrialized housing industry, Lean Construction Journal: 1-12.

Ohno, T. 1988. Toyota production system. Cambridge: Productivity Press. 143 p.

Peng, Y. H. 1991. Investigation and analysis of Taiwan construction energy. Research Report, Architecture and Building Research Institute, Ministry of the Interior, Taipei, Taiwan (in Chinese).

Peng, Y. H. 1992. Investigation and analysis of Taiwan construction energy II. Research Report, Architecture and Building Research Institute, Ministry of the Interior, Taipei, Taiwan (in Chinese).

Peng, Y. H. 1998. Consulting service for automation in architectural engineering. Research Report, Architecture and Building Research Institute, Ministry of the Interior, Taipei, Taiwan (in Chinese).
Picchi, F. A.; Granja, A. D. 2004. Construction sites: using lean principles to seek broader implementations, in Proceedings of the $12^{\text {th }}$ Annual Conference of the International Group for Lean Construction, 3-5 August 2004, Copenhagen, Demark, 1-12.

Sacks, R.; Dave, B.; Koskela, L. J.; Owen, R. L. 2009, Analysis framework for the interaction between lean construction and building information modelling, in Proceedings of the $17^{\text {th }}$ Annual Conference of the International Group for Lean Construction, 15-17 July 2009, Taipei, Taiwan, 221-234.

Sheikh, S. A.; Jaffry, S. A. D.; Cui, C. 2007. Investigation of glass-fibre-reinforced-polymer shells as formwork and reinforcement for concrete columns, Canadian Journal of Civil Engineering 34(3): 389-402. http://dx.doi.org/10.1139/106-110

Shen, C. F. 1996. Formwork engineering: economic, design, assembly, and safety. Taipei: Shen Publisher, 8-15 (in Chinese).

Spottiswoode, A. J.; Bank, L. C.; Shapira, A. 2012. Investigation of paperboard tubes as formwork for concrete bridge decks, Construction and Building Materials 30: 767-775. http://dx.doi.org/10.1016/j.conbuildmat.2011.12.033

Sutherland, M. 2005. Formwork economics, Concrete Engineering International 9(4): 18-19.

Umit Dikmen, S.; Sonmez, M. 2011. An artificial neural networks model for the estimation of formwork labour, Journal of Civil Engineering and Management 17(3): 340-347. http://dx.doi.org/10.3846/13923730.2011.594154

Veenendaal, D.; West, M.; Block, P. 2011. History and overview of fabric formwork: using fabrics for concrete casting, Structural Concrete 12(3): 164-177. http://dx.doi.org/10.1002/suco.201100014

Yip, R.; Poon, C. S. 2008. Comparison of timber and metal formwork systems, in Proceedings of Institution of Civil Engineers: Waste and Resource Management 161(1): 29-36.

Zhuo, L. Y.; Yaung, Z. B. 2004. Problem analysis for adopting new architectural formwork systems to in Taiwan, Modern Construction 293: 31-35 (in Chinese).

Chien-Ho KO. A Professor at the Department of Civil Engineering at National Pingtung University of Science and Technology, Taiwan. He received a BS in Construction Engineering from National Taiwan Institute of Technology in 1997, and a MS and PhD from National Taiwan University of Science and Technology in 1999 and 2002 respectively. He conducted his postdoctoral research work at the University of California at Berkeley, USA from 2004 to 2005, sponsored by the Ministry of Education, Taiwan. He is a registered Professional Engineer of Fire Protection and a member of Taipei Association of Fire Protection Engineer. He is a cofounder and research director at Lean Construction Institute-Taiwan, and co-founder and executive director at Lean Construction Institute-Asia. He is serving as Editorial Board Member for more than 11 international journals, and he is also serving as Editor-inChief of the Journal of Engineering, Project, and Production Management (EPPM-Journal). His research has centered around lean construction, computational algorithms, robotics, and engineering education.

Jiun-De KUO. An Engineer Researcher in the Information Center of Construction Industry, Taiwan Construction Research Institute. He received a MS from the Civil Engineering Department at National Pingtung University of Science and Technology. Before this graduate study, he was an engineer in a professional construction management company. His research focuses on improving formwork engineering. 